\title{
MICROEMULSION OF BRAZIL NUT OIL AS A NATURAL PRODUCT TO IMPROVE SUPEROXIDE RELEASE IN HUMAN PHAGOCYTES
}

\author{
Karol Patel Fioria, Maycon de Paula Ribeiro Torres ${ }^{\mathrm{a}}$, Jessica Iara Schons ${ }^{\mathrm{a}}$, Elton Brito Ribeiro ${ }^{\mathrm{a}}$, Roberta Martins Nogueira ${ }^{\mathrm{b}}$, \\ Leonardo G. Vasconcelos ${ }^{\mathrm{c}}$, Carla R. Andrighettia ${ }^{\mathrm{a}}$, Marcos José Jacinto ${ }^{\mathrm{c}}$ e Denia M. de S. Valladão,* \\ anstituto de Ciências da Saúde, Universidade Federal de Mato Grosso, 78557-267 Sinop - MT, Brasil \\ 'Instituto de Ciências Agrárias e Ambientais, Universidade Federal de Mato Grosso, 78557-267 Sinop - MT, Brasil \\ 'Departamento de Química, Universidade Federal de Mato Grosso, 78060-900, Cuiabá - MT, Brasil
}

Recebido em 25/05/2017; aceito em 29/06/2017; publicado na web em 29/08/2017

\begin{abstract}
The aim of this study was to develop and characterize a Brazil nut oil microemulsion system and determine the effect of this microemulsion on the superoxide release in human phagocytes. The microemulsion was formulated using distilled water, Brazil nut as the oily phase, Sorbitan monooleate, Polysorbate 80, and butan-1-ol. Hydrophile-lipophile balance of Brazil nut oil was determined, pseudoternary diagrams were prepared, and microemulsion diagram regions were preselected. Preliminary and accelerated stability tests, rheological characterization and dynamic light scattering were performed. The immunomodulatory effect of the microemulsion on the interactions with leukocytes was determined by superoxide release. The developed formulations were classified as oil-in-water, showed a Newtonian profile, with linear viscosity and droplet sizes of 46.9; 66.5 and $34.3 \mathrm{~nm}$. When we assessed the interaction of the microemulsion of Brazil nut oil with phagocytes, we observed an increase in superoxide release. Our findings indicate that the developed formulation improved the immunomodulatory activity of the Brazil nut oil, proving to be a natural product option for future applications, in particular for infectious diseases.
\end{abstract}

Keywords: vegetable oil; Brazil nut; microemulsion; phagocytes; delivery systems.

\section{INTRODUCTION}

The use of nanotechnology to produce micro and nanostructured systems has been increasing due to their important use as agents to dissolve active ingredients which improves the physical and chemical stability, and maintains the drug or cosmetic as an active ingredient effect in the tissue, minimizing the side effect and reducing toxicity. ${ }^{1-5}$ Microemulsions have also been identified as potential delivery systems for bioactives in foods, pharmaceutical and cosmetic formulations. ${ }^{6}$

There are several types of nanostructures, and microemulsions (MEs) are one of them, that can be used as carriers for lipophilic bioactive compounds, drugs or nutrients..$^{7-10}$

MEs are thermodynamically stabilized oil-water dispersions (100 nm droplets) that are macroscopically homogeneous, translucent and stabilized by a surfactant and cosurfactant interfacial film. ${ }^{11-15}$

The formation of MEs involves a combination of three to five components, such as surfactant, water, oil, and a cosurfactant if necessary. ${ }^{16,17}$ The orientation for oil-in-water $(\mathrm{O} / \mathrm{W})$ or water-in-oil (W/O) depends on the surfactant and oil physicochemical properties, on the relation between surfactant/cosurfactant proportions, as well as water/oil proportions. ${ }^{18,19}$

Lately, the search for bioactive compounds has increased, and according to the literature the adsorption of extracts and molecules with lipophilic nature or lipids, as well as vegetable oils, can be enhanced when combined to nanocarriers. ${ }^{20,21}$

Some vegetable oils obtained from seeds hold interesting amounts of bioactive compounds, and therefore have become an important field of research. Phenolic acids, flavonoids, flavonols, phytosterols, tocopherols, and anthocyanins, ${ }^{22-24}$ as well as some fatty acids (oleic, linoleic, and palmitic) present important therapeutic effects in response to pathogenic microorganisms. ${ }^{25,26}$ This is due to cellular

*e-mail: deniavalladao@gmail.com stimulation, which can be observed by the activation of oxidative metabolism in a modulated form. ${ }^{27,28}$ The oxidative metabolism can be evaluated by the quantification of oxygen consumption or the formation of derivatives from cellular oxidative metabolism, superoxide anion being among them. ${ }^{29,30}$ In this context, Brazil nut stands out for presenting high content of oil (around 45,2\%), comprising palmitic, stearic, oleic, and linoleic acids, ${ }^{31}$ vitamins, minerals, ${ }^{32-34}$ and other compounds, such as tannins, ellagic acid, curcumin, flavonoids, and isoflavones. ${ }^{35}$

Then, the aim of this study was to develop and characterize a Brazil nut oil microemulsion system and evaluate the effect of this microemulsion on the superoxide release in human phagocytes.

\section{EXPERIMENTAL}

\section{System composition}

The Brazil nut oil was provided by Borello Industry, Sinop MT, Brazil. The MEs systems were formulated using Brazil nut oil, distilled water, sorbitan monostearate (Span $80-\mathrm{SP}$ ), HLB = 4,3; polysorbate 80 (Tween 80 - TW), HLB = 15,0; and butan-1-ol (BT). These reagents used in the study were analytical grade and purchased from Sigma ${ }^{\circledR}$, USA.

\section{Hydrophile-lipophile Balance (HLB) Determination of Brazil nuts oil}

The mixture of surfactants fractions for SP and TW and the ratio (w/w) of the surfactants to obtain the HBL (6 up to 12) was calculated.

Several samples in triplicate of serial emulsions were prepared by heating in an electric water bath at $75{ }^{\circ} \mathrm{C}$. The water and oily phases were prepared separately, and then mixed and kept under manual stirring and heating for $15 \mathrm{~min}$. Then, the emulsions were removed from the bath, and kept under manual stirring for fifteen 
minutes at room temperature. The prepared emulsions were aged for 24 hours at room temperature. Emulsions were analyzed under BEL $^{\circledR}$ Photonics microscope at $40 \times$ magnification and the globules photographed for later determination of their area using the Image $J$ software. Coefficient of variation in function of the globules area was calculated.

\section{Determination of the surfactant mixing ratio}

Butan-1-ol (BT) was used in a ratio equivalent to $10 \%(\mathrm{Fc}=1)$ of the surfactant mixture. BT is considered one of the best cosurfactants for the preparation of microemulsion ${ }^{11,36-38}$ and the concentration used in this study is considered residual and non-toxic. ${ }^{39}$

The HLB of the surfactant mixture and the composition required to achieve an HLB corresponding to the oily phase was calculated. The HLB of the SP and TW surfactants were taken into account, according to Ribeiro. ${ }^{40}$

\section{Microemulsion systems development}

Development of formulations utilized pre-established quantities of the components in which each component ranged from $10 \%$ to $80 \%$. The samples were visually assessed after 72 hours at $25^{\circ} \mathrm{C}$ in the following point: microemulsion, gel emulsion, and phase separation.

Titrations were performed on aqueous mixtures with surfactant/ oily phase mass ratios of 1:9 and 9:1 under agitation to obtain the delimiting points, area and classification of different systems to form the diagram regions. The titration was performed by adding distilled water in quantities between $0.05 \mathrm{~mL}$ and $0.20 \mathrm{~mL}$. During this process, the mixture was agitated both manually and mechanically. After homogenization of each titrant, the formulations were visually classified.

Diagrams to define the composition of each type of formulation were constructed from data attained using Sigma Plot 8.0 software. After pseudoternary diagram acquisition, compositions of the systems that fell into the ME region were defined. This region containing preselected points was distributed in lines, dividing the region due to achieve representative samples, which were later characterized and submitted to stability studies.

\section{Characterization}

Some properties were tested to verify the possibility of the formulations to act as delivery vehicles and to carry out the initial characterization of each sample. The tests were performed 24 hours after preparation and at the stability study and in triplicate.

Aliquots of some MEs preselected vehicles were centrifuged (Fanem ${ }^{\circledR}$, Brazil) at $3600 \mathrm{rpm}$ for 30 minutes at room temperature. After centrifugation, the samples with visual heterogeneity were excluded.

The $\mathrm{pH}$ of the MEs was determined with a pHmeter (Tecnopon ${ }^{\circledR}$, Brazil) calibrated with $\mathrm{pH} 7$ and $\mathrm{pH} 4$ standard solutions. The electrical conductivity was measured using a Conductivity Meter (Tecnopon $^{\circledR}$, Brazil) calibrated with a $0.1 \mathrm{~mol} \mathrm{~L}^{-1} \mathrm{KCl}$ solution to identify the system type (water in oil or oil in water) and any tendency towards to phase inversion. Refractive index was obtained by inserting a sample droplet on the measuring prism surface in Abbe Digital Refractometer (Polax, China) to indicate possible appearance of instabilities or liquid crystals.

\section{Stability studies}

Samples MEs were divided into two groups according to temperature: those that were refrigerated at $5 \pm 1{ }^{\circ} \mathrm{C}$ and those that were heated at $40 \pm 1{ }^{\circ} \mathrm{C}$. These systems were preliminarily subjected to alternating cycles of $5 \pm 1{ }^{\circ} \mathrm{C}$ and $40 \pm 1{ }^{\circ} \mathrm{C}$ for 24 hours each, and the cycles were completed on the $14^{\text {th }}$ day. After the cycles, it was possible to identify the most thermodynamically stable formulations.

The formulations were subjected to extreme conditions to determine their stability over a long period. The systems were divided into three groups according to temperature: $5 \pm 1{ }^{\circ} \mathrm{C}, 25 \pm 1{ }^{\circ} \mathrm{C}$, and $40 \pm$ $1{ }^{\circ} \mathrm{C}$. The groups were assessed in triplicate for a period of 90 days. Every 30 days, the formulations were maintained at room temperature for 24 hours to determine the physicochemical properties.

\section{Rheological characterization}

The rheological parameters were determined by Modular Compact Rheometer (Anton Paar ${ }^{\circledR}$, Germany). In all trials, $600 \mu \mathrm{L}$ of each formulation were placed on the surface of the reading plate. Data were taken with continuous control of the gap measurement using the support TruGap ${ }^{\mathrm{TM}}$ in $0.099 \mathrm{~mm}$. The measuring cell was a Toolmaster ${ }^{\mathrm{TM}} \mathrm{CP} 50$, and precise temperature control was achieved through T-Ready ${ }^{\mathrm{TM}}$. Acquired data were treated using the Rheoplus V3.61 software. The flow and viscosity curves were displayed using established parameters considering the control of shear stress $(\tau)$ in the 0-5 Pa range for the upsweep and 5-0 Pa for the curve downward. These measurements were performed under isothermal conditions at $25^{\circ} \mathrm{C}$, comprising 75 readings per analysis.

\section{Dynamic Light Scattering (DLS)}

The mean globular size was measured at $25^{\circ} \mathrm{C}$ by dynamic light scattering (DLS) using a Malvern Zetasizer Nano ZS (Malvern ${ }^{\circledR}$, United Kingdon), $632.8 \mathrm{~nm}$ excitation. Colloidal suspension samples (in triplicate) were prepared from a 10:1000 dilution of the formulation.

\section{Blood sampling and blood cell separation}

Samples of $15 \mathrm{~mL}$ of blood were collected from 15 healthy volunteers, both sexes and aged 18 to 30 . Blood samples were stored in EDTA (25 units of anticoagulant per $\mathrm{mL}$ of blood) tubes. This study was submitted to the institutional Research Ethics Committee, and all of the subjects gave written informed consent before entering the experimental protocol. After the collection procedure, the samples were centrifuged at $1500 \mathrm{rpm}$ for $40 \mathrm{~min}$ at room temperature, to isolate plasma from the cells. Cells were separated over a Ficoll-Paque gradient (Pharmacia, Sweden) to produce samples with 95\% pure mononuclear cells as analyzed by light microscopy. The enriched mononuclear phagocytes ring was removed and reserved. Mononuclear cells were washed twice in phosphate-buffered saline (PBS), setting up the concentration to $2 \times 10^{6}$ cells $\mathrm{mL}^{-1}$, using a Neubauer chamber, being available for further analyses.

\section{Superoxide anion aelease of phagocyte treatment with Brazil nut oil and ME}

Superoxide release was determined by reduction of cytochrome C $\left(\right.$ Sigma-Aldrich $\left.{ }^{\circledR}\right)$. Briefly, cells were then re-suspended in PBS with cytochrome $\mathrm{C}\left(2 \mathrm{mg} \mathrm{mL}^{-1}\right)$ and Brazil nut oil $(50 \mu \mathrm{L})$ or Brazil nut $\mathrm{ME}(\mathrm{s})(50 \mu \mathrm{L})$ was added. The suspensions $(100 \mu \mathrm{L})$ were incubated for zero, 1,2 and 24 hours at $37^{\circ} \mathrm{C}$ on culture plates. A control was performed using only the spontaneous release of cells. The reaction rates were measured by absorbance at $550 \mathrm{~nm}$ and the results were expressed as nmol $\mathrm{O}^{-2}$. 


\section{Statistical application}

Statistical analyses were performed using the BioEstat 5.0 software. Statistically significant differences in antioxidant activity and superoxide anion release in the presence of Brazil nut oil and microemulsions were evaluated using analysis of variance (ANOVA) and Tukey's multiple comparison tests. Statistical significance was considered when the p-value was less than $0.05(\mathrm{P}<0,05)$.

\section{RESULTS AND DISCUSSION}

In this investigation, three stable oil-in-water microemulsion formulations were selected with Brazil Nut oil after constructing diagrams that demonstrated linear viscosity and a Newtonian profile. These formulations improved the immunomodulatory activity of the Brazil Nut oil highlighted by the increase of superoxide anion release of human blood MN cells and its ability to interact with blood phagocytes.

To determine the HLB of Brazil nut oil in the oil phase, the SP and TW surfactants were mixed with distilled water to obtain an HLB between 6 and 12. After the emulsification, the coefficient of variation of the area of the globules (Figure 1) was calculated. It was observed that the emulsion systems with lower coefficient of variation were more homogeneous and the globules with coefficient of variation of 0.55 and area of $0.01 \mathrm{~mm}^{2}$ were the most uniform in diameter and distribution, with no aggregation, resulting in HLB of 10 for Brazil nut oil. Microscopic evaluations for the determination of the HLB of vegetable oils have been widely used in the literature, ${ }^{41}$ but there are few studies regarding the determination of the area of the globules. Thus, the development of a simple, efficient and cheap method that does not require the use of any sophisticated equipment is of great interest.

To determine the surfactant mixing ratio, the co-surfactant concentration was fixed as $10 \%$, and the amount of surfactants SP and TW were calculated to achieve the required Brazil Nut oil (HLB = 10). The obtained surfactant fractions were 4.2 and 4.8 for SP and TW, respectively, resulting in the mix relation of 4.2:4.8:1.0 (SP:TW:BT).

Phase behavior studies were performed by constructing pseudoternary phase diagrams providing information on the boundaries of the different phases as a function of composition of oily phase (Brazil Nut oil), aqueous phase and surfactant mix (4.2:4.8:1.0), varying from 10 to $80 \%$, of the formulation (Figure 2).

These data resulted in 36 points with different equilibrium characteristics. Homogeneous and translucent systems can be predominantly observed in the region with surfactant mix higher than $55 \%$ indicating points with thermodynamic equilibrium characteristic (Figure $2 \mathrm{a}$ ). The Figure $2 \mathrm{~b}$ displays the pseudoternary diagram with delimited domains, attained from the diagram points and aqueous titrations. Through the analysis of phase behavior, it is possible to classify different regions as liquid ME, gelling (GE) and phase separation (SF). Analysis of the phase behavior indicated that a large range of surfactant compositions produced stable systems. However, when the domain surfactant mix concentration is below $50 \%$, some instability and phase separation were also observed, indicating that these surfactant concentrations could not balance high proportions of aqueous and oily phases (Figure 2b). The samples labeled 1 to $10 \mathrm{MC}$ were pre-selected and showed clear, yellowish systems, corresponding to the microemulsion region. These MEs appeared dark under polarized light microscope (no birefringence), confirming their isotropic character of $\mathrm{ME}(\mathrm{s})$. Then pre-selected MEs were submitted to physicochemical studies.

Some parameters as centrifugation (1500 rpm for 30 minutes), freeze/defrost cycles and stress thermal were used to investigate the preliminary stability for 14 days and the results are listed in Table 1. The samples with no phase separation were considered normal (N). Further, it was observed that samples 1, 2, 7,9 and $10 \mathrm{MC}$ presented a visually normal behavior, remaining translucent before and after the stability test, showing high stability. However, formulations 3, 4, 5, 6 and $8 \mathrm{MC}$ presented visual change after the stability test and further stability tests for these samples could not be pursued. Afterwards, the formulations 1, 2, 7, 9 and $10 \mathrm{MC}$ were submitted to the accelerated stability studies, which are listed in Table 2.

The conductivity measurements are used to classify $\mathrm{ME}$ as $\mathrm{O} / \mathrm{W}$ or $\mathrm{W} / \mathrm{O}^{38}$ and according to conductivity data, all formulations were classified as $\mathrm{O} / \mathrm{W}$ because they had electrical conductivity values above that of distilled water $\left(>1.3 \mu \mathrm{S} \mathrm{cm}^{-1}\right)$. The $\mathrm{pH}$ values obtained before and after the stability tests remained between 6.0 and 7.0, showing small variation, compared to the values attained before the treatment, while conductivity values are consistent with $\mathrm{O} / \mathrm{W}$ pattern over the whole trial period. The formulations also presented a small variation on the refraction values throughout the time. The values remained around 1.44 and 1.45 which confirms the stability of the systems during the entire trial.

Rheological characterization was performed by attaining the flow and viscosity curves, as a function of shear rate. Initially, flow curves of the MC formulations (1, 2, 7, 9 and $10 \mathrm{MC}$ ) we measured (Figure 3a). It is observed that for all samples the flow curve began at the origin and then exhibited linear ascending, and descending behavior, indicating that these formulations behave as Newtonian fluids. In addition, viscosity curves of samples passing the first test, as a function of shear rate, are displayed in Figure $3 \mathrm{~b}$. It is noted that the viscosity values did not change as the shear increased $(0.15$ and 0.25 Pas).

Droplet size analysis and particle size distribution attained by the DLS technique for samples 1, 2, 7, 9 and $10 \mathrm{MC}$ are displayed in Figure 4. It is observed that formulation 1, 2 and $7 \mathrm{MC}$ present lower sizes and thinner distribution, compared with 9 and $10 \mathrm{MC}$ formulations. Therefore, up to this point, the pre-selected samples

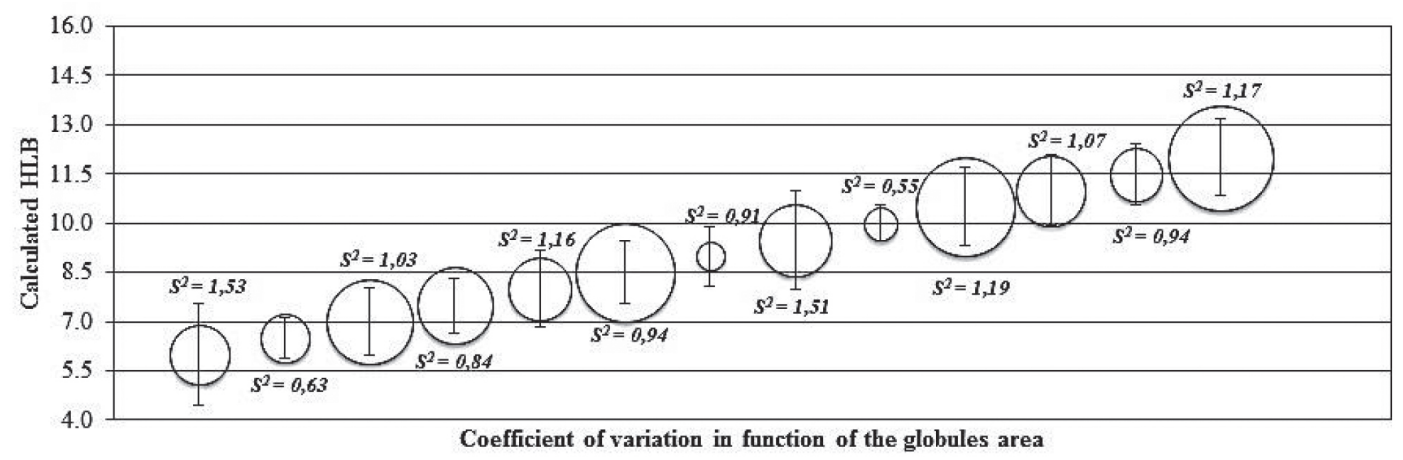

Figure 1. Coefficient of variation of the globules area of emulsions containing Brazil Nut oil with calculated HLB 
are $1 \mathrm{MC}, 2 \mathrm{MC}$ and $7 \mathrm{MC}$ presented lower distribution.

In particular, the O/A MEs of Brazil Nut oil, presented Newtonian profile and no change in the hysteresis area and linear viscosity,

a)

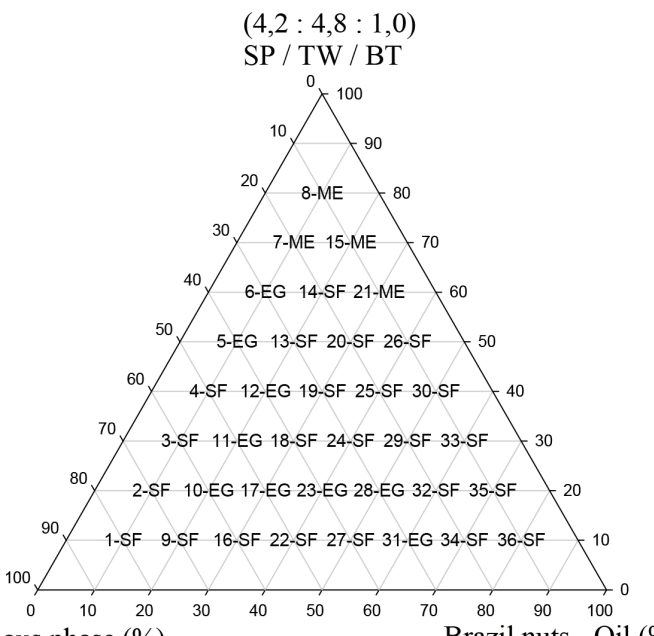

Aqueous phase (\%)

b)

$(4,2: 4,8: 1,0)$

$\mathrm{SP} / \mathrm{TW} / \mathrm{BT}$

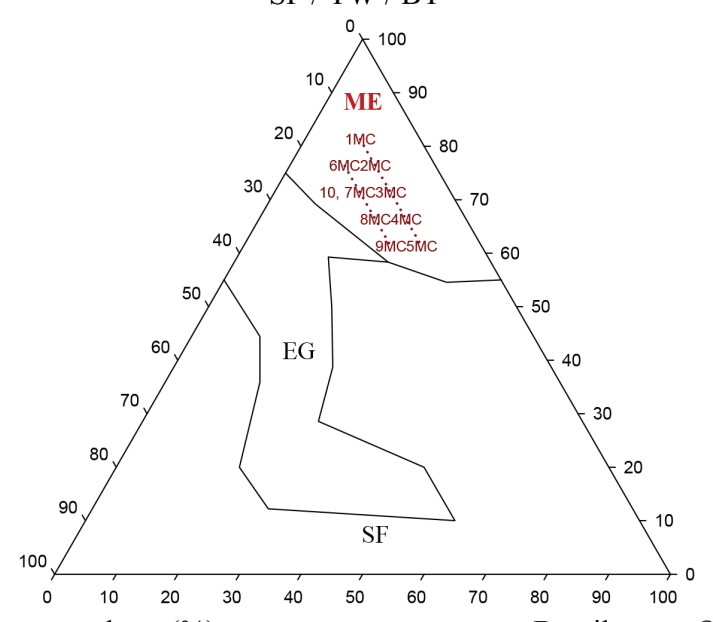

Aqueous phase (\%)

Brazil nuts - Oil (\%)

Figure 2. Pseudoternary diagrams indicating microemulsion (1MC to 10MC) regions, classification of points (a) and region domains for the selected microemulsions (b) SP/TW/PG system.Abbreviations: microemulsion (ME), gel emulsion (EG), Phase Separation (SF) during the time gap investigated. In addition, $1 \mathrm{MC}, 2 \mathrm{MC}$ and $7 \mathrm{MC}$ had their nanometric hydrodynamic size, maintenance of $\mathrm{pH}$ values and refractive index. Therefore, our findings indicate that $1 \mathrm{MC}, 2 \mathrm{MC}$ and $7 \mathrm{MC}$ formulations presented the highest stability parameters and were selected to perform biological assays.

Several other studies have also demonstrated that stimulus such as medicinal plants, ${ }^{42-45}$ hormones ${ }^{46,47}$ and cytokines ${ }^{4,48}$ can increase the release of superoxide anions from mononuclear phagocytes.

The evaluation of the superoxide anion released by the human peripheral blood cells in the presence of different stimulus (1MC, $2 \mathrm{MC}$, and $7 \mathrm{MC}$, and the Brazil nut oil, and $\mathrm{PBS}$ ) and incubation timing $(0 ; 1 ; 2$; and 24 hours) are presented in Figure 5.

When the MN phagocytes were treated with the microemulsions containing Brazil nut oil, the anion release was meaningfully higher than the spontaneous one (PBS). The anion release seems to be influenced by the globular diameter of the formulation and by the incubation time (Figure 4).

Mononucleated cells performed an important role on the host defense. The monocytes originate macrophages and myeloid dendritic cells in the connective tissue or parenchyma of organs. The monocytes and macrophages are efficient phagocytes, engulfing pathogens and cell debris. ${ }^{49,50}$ They produce phagocyte oxidase NADPH, which formulates the active superoxide to absorb bacteria, and it is essential for the immune responses and inflammatory reactions success. ${ }^{51}$ Certain studies based on nanostructured systems designed to stimulate the phagocyte activity are found in literature, to our best knowledge there is no previous study for the Brazil nut oil.

In this work, when comparing the microemulsion formulations according to the hydrodynamic diameter, the blood monocytes present higher anion release for the formulations from lowest to highest diameter $(7 \mathrm{MC}<1 \mathrm{MC}<2 \mathrm{MC})$, respectively. Comparing the same treatment with the formulations developed according to timing (from 0 to 24 hours), the blood monocytes presented immediate stimulation efficiency (time 0) compared to the controls (PBS, oil), following with gradual increase of stimulation, where as the Brazil nut oil presented equivalent activity to the spontaneous group over time. Similar results for the immunomodulatory activity on the superoxide release by phagocytes when stimulated by babassu oil microemulsion were found in literature. ${ }^{3}$

The formulation 7MC was the one which promoted the most significant stimulation in all the timings. These results can derive from the permeabilization and interaction of the developed system with the cells. A similar effect can not be observed for the pure oil. The blood cells/nanosystems interaction is an important feature, since the insourcing process depends on the nanostructure concentration and

Table 1. Preliminary stability tests of preselected microemulsions (1MC to 10MC)

\begin{tabular}{|c|c|c|c|c|c|c|c|c|c|c|}
\hline \multicolumn{11}{|c|}{ Preliminary stability } \\
\hline \multirow{2}{*}{ Parameters before cycles } & \multicolumn{10}{|c|}{ Formulation } \\
\hline & $1 \mathrm{MC}$ & $2 \mathrm{MC}$ & $3 \mathrm{MC}$ & $4 \mathrm{MC}$ & $5 \mathrm{MC}$ & $6 \mathrm{MC}$ & $7 \mathrm{MC}$ & $8 \mathrm{MC}$ & $9 \mathrm{MC}$ & $10 \mathrm{MC}$ \\
\hline Centrifugation & $\mathrm{N}$ & $\mathrm{N}$ & $\mathrm{N}$ & $\mathrm{N}$ & $\mathrm{N}$ & $\mathrm{N}$ & $\mathrm{N}$ & $\mathrm{N}$ & $\mathrm{N}$ & $\mathrm{N}$ \\
\hline $\mathrm{pH}$ & $6.69 \pm 0.10$ & $6.44 \pm 0.13$ & $6.39 \pm 0.54$ & $6.53 \pm 0.77$ & $6.27 \pm 0.49$ & $6.24 \pm 0.54$ & $6.53 \pm 0.52$ & $6.32 \pm 0.49$ & $6.92 \pm 0.11$ & $6.53 \pm 0.32$ \\
\hline Conductivity $\left(\mu \mathrm{S} \mathrm{cm}^{-1}\right)$ & $6.90 \pm 0.25$ & $7.19 \pm 0.64$ & $7.35 \pm 1.48$ & $2.04 \pm 1.00$ & $9.43 \pm 1.13$ & $16.36 \pm 0.76$ & $11.38 \pm 0.48$ & $12.29 \pm 0.75$ & $16.13 \pm 2.83$ & $18.85 \pm 0.01$ \\
\hline Refraction Index & $1.4542 \pm 1 \mathrm{e}-3$ & $1.4515 \pm 2 \mathrm{e}-4$ & $1.4529 \pm 2 \mathrm{e}-4$ & $1.4536 \pm 1 \mathrm{e}-4$ & $1.4538 \pm 4 \mathrm{e}-4$ & $1.4463 \pm 3 e-4$ & $1.4478 \pm 3 e-3$ & $1.4462 \pm 5 \mathrm{e}-4$ & $1.4485 \pm 1 \mathrm{e}-3$ & $1.4448 \pm 4 \mathrm{e}-4$ \\
\hline \multicolumn{11}{|l|}{ Parameters after cycles } \\
\hline Aspect & $\mathrm{N}$ & $\mathrm{N}$ & A & A & A & A & $\mathrm{N}$ & A & $\mathrm{N}$ & $\mathrm{N}$ \\
\hline $\mathrm{pH}$ & $6.76 \pm 0.19$ & $6.71 \pm 0.04$ & $6.73 \pm 0.08$ & $6.78 \pm 0.51$ & $6.96 \pm 0.25$ & $6.72 \pm 0.15$ & $6.67 \pm 0.04$ & $6.41 \pm 0.14$ & $6.61 \pm 0.13$ & $6.76 \pm 0.16$ \\
\hline Conductivity $\left(\mu \mathrm{S} \mathrm{cm}^{-1}\right)$ & $7.77 \pm 1.18$ & $7.48 \pm 0.52$ & $8.22 \pm 0.04$ & $9.94 \pm 0.93$ & $10.36 \pm 0.49$ & $16.82 \pm 1.24$ & $11.60 \pm 1.09$ & $9.56 \pm 4.47$ & $12.11 \pm 1.92$ & $12.70 \pm 1.09$ \\
\hline Refraction Index & $1.4538 \pm 1 \mathrm{e}-3$ & $1.4531 \pm 3 e-4$ & $1.4531 \pm 5 e-4$ & $1.4549 \pm 2 \mathrm{e}-3$ & $1.4537 \pm 6 e-4$ & $1.4464 \pm 8 \mathrm{e}-4$ & $1.4491 \pm 8 \mathrm{e}-4$ & $1.4543 \pm 1 \mathrm{e}-4$ & $1.4600 \pm 4 \mathrm{e}-3$ & $1.4476 \pm 8 \mathrm{e}-4$ \\
\hline
\end{tabular}

Where: $\mathrm{N}=$ Normal and $\mathrm{A}=$ Change Visual. 
Table 2. Accelerated stability tests obtained of the formulations 1, 2, 7, 9 and $10 \mathrm{MC}$

\begin{tabular}{|c|c|c|c|c|}
\hline \multirow{3}{*}{ Formulation } & \multicolumn{4}{|c|}{$\mathrm{pH}$} \\
\hline & \multicolumn{4}{|c|}{ Time (days) } \\
\hline & 0 & 30 & 60 & 90 \\
\hline $1 \mathrm{MC}$ & $6.83 \pm 0.26$ & $6.53 \pm 0.41$ & $6.49 \pm 0.20$ & $6.44 \pm 0.33$ \\
\hline $2 \mathrm{MC}$ & $6.69 \pm 0.23$ & $6.73 \pm 0.14$ & $6.60 \pm 0.25$ & $6.58 \pm 0.43$ \\
\hline $7 \mathrm{MC}$ & $6.96 \pm 0.02$ & $6.65 \pm 0.19$ & $6.55 \pm 0.22$ & $6.64 \pm 0.40$ \\
\hline $9 \mathrm{MC}$ & $6.60 \pm 0.15$ & $6.61 \pm 0.19$ & $6.49 \pm 0.17$ & $6.50 \pm 0.36$ \\
\hline \multirow[t]{2}{*}{$10 \mathrm{MC}$} & $6.27 \pm 0.21$ & $6.56 \pm 0.17$ & $6.56 \pm 0.47$ & $6.55 \pm 0.25$ \\
\hline & \multicolumn{4}{|c|}{ Conductivity $\left(\mu \mathrm{S} \mathrm{cm}^{-1}\right)$} \\
\hline \multirow[t]{2}{*}{ Formulation } & \multicolumn{4}{|c|}{ Time (days) } \\
\hline & 0 & 30 & 60 & 90 \\
\hline $1 \mathrm{MC}$ & $5.32 \pm 0.08$ & $5.68 \pm 0.30$ & $7.81 \pm 0.28$ & $5.70 \pm 1.79$ \\
\hline $2 \mathrm{MC}$ & $4.86 \pm 0.12$ & $5.30 \pm 0.19$ & $7.34 \pm 0.38$ & $5.27 \pm 1.30$ \\
\hline $7 \mathrm{MC}$ & $8.60 \pm 0.16$ & $9.57 \pm 0.42$ & $9.36 \pm 0.08$ & $9.14 \pm 1.00$ \\
\hline $9 \mathrm{MC}$ & $9.60 \pm 0.09$ & $9.90 \pm 0.17$ & $9.43 \pm 0.21$ & $9.18 \pm 1.19$ \\
\hline \multirow[t]{2}{*}{$10 \mathrm{MC}$} & $14.21 \pm 0.06$ & $15.79 \pm 0.70$ & $9.88 \pm 0.06$ & $13.76 \pm 2.02$ \\
\hline & \multicolumn{4}{|c|}{ Refraction Index } \\
\hline \multirow[t]{2}{*}{ Formulation } & \multicolumn{4}{|c|}{ Time (days) } \\
\hline & 0 & 30 & 60 & 90 \\
\hline $1 \mathrm{MC}$ & $1.4574 \pm 1 \mathrm{e}-4$ & $1.4570 \pm 1 \mathrm{e}-3$ & $1.4555 \pm 4 \mathrm{e}-4$ & $1.4567 \pm 5 \mathrm{e}-4$ \\
\hline $2 \mathrm{MC}$ & $1.4571 \pm 1 \mathrm{e}-4$ & $1.4572 \pm 1 \mathrm{e}-3$ & $1.4557 \pm 4 \mathrm{e}-4$ & $1.4567 \pm 6 \mathrm{e}-4$ \\
\hline $7 \mathrm{MC}$ & $1.4530 \pm 8 \mathrm{e}-4$ & $1.4528 \pm 1 \mathrm{e}-3$ & $1.4510 \pm 4 \mathrm{e}-4$ & $1.4519 \pm 6 \mathrm{e}-4$ \\
\hline $9 \mathrm{MC}$ & $1.4532 \pm 4 \mathrm{e}-4$ & $1.4530 \pm 1 \mathrm{e}-3$ & $1.4519 \pm 9 \mathrm{e}-4$ & $1.4513 \pm 3 \mathrm{e}-3$ \\
\hline $10 \mathrm{MC}$ & $1.4477 \pm 2 \mathrm{e}-4$ & $1.4482 \pm 2 \mathrm{e}-3$ & $1.4477 \pm 2 \mathrm{e}-3$ & $1.4464 \pm 4 \mathrm{e}-4$ \\
\hline
\end{tabular}
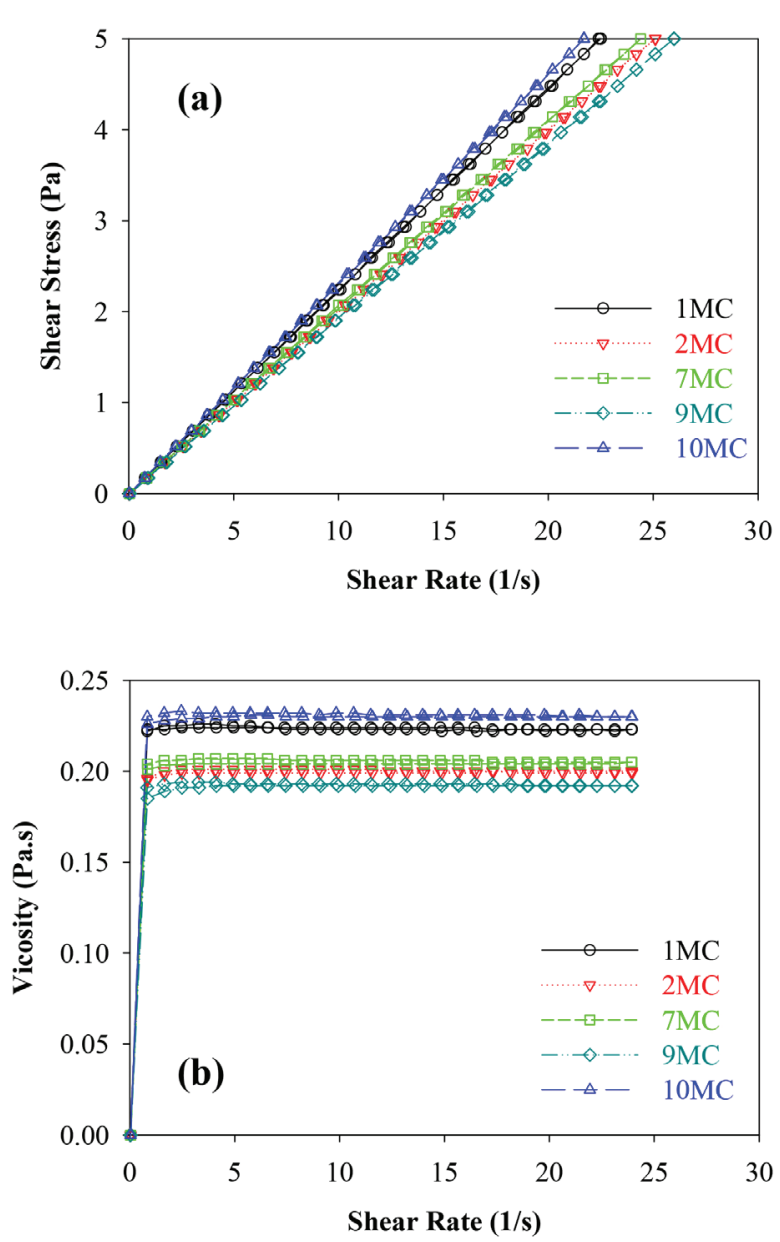

Figure 3. Flow curve (a), viscosity (b) at $25^{\circ} \mathrm{C}$ of micoemulsion of Brazil Nut oil (1, 2, 7, 9 and $10 \mathrm{MC})$ the hydrodynamic diameter. ${ }^{22,53}$ These characteristics can be directly linked to the superoxide anion release stimulation.

The improved performance of the active molecules in nanostructured systems as vehicles can be related to the optimization of pharmacokinetic parameters, metabolic stability, the great membrane permeability, ${ }^{54}$ various nanodrug systems have been developed for different routes of administration, which include dendrimers, nanocrystals, emulsions, liposomes, solid lipid nanoparticles, micelles, and polymeric nanoparticles. Nanodrug systems have been employed to improve the efficacy, safety, physicochemical properties, and pharmacokinetic/pharmacodynamic profile of pharmaceutical substances. In particular, functionalized nanodrug systems can offer enhanced bioavailability of orally taken drugs, prolonged half-life of injected drugs (by reducing immunogenicity and also, as observed in the developed formulations, the increase in operation time.

The developed microemulsions showed remarkable results for the length of time and potential of phagocyte stimulation, when compared to the stimulation of functional activity of leukocytes and bacteria experiments. . $^{30,55-58}$

Generation of free radicals is reportedly as an important organismal defense mechanism during infectious processes..$^{30,51,59,60}$ In this work, it was found that both MEs of Brazil Nut oil increased the release of superoxides from human blood phagocytes. The control of functional activity of blood cells observed by ME of Brazil nut oil was likely generated by interaction between the components of the ME formulation. Future studies should be conducted to verify the potential of this formulation as an adjuvant for delivery of vaccines, treatment of infections, parasitic and cancer diseases that promote an immunomodulation.

\section{CONCLUSION}

The study demonstrated that a poorly water-soluble bioactive lipid with possible low bioavailability can be formulated as 


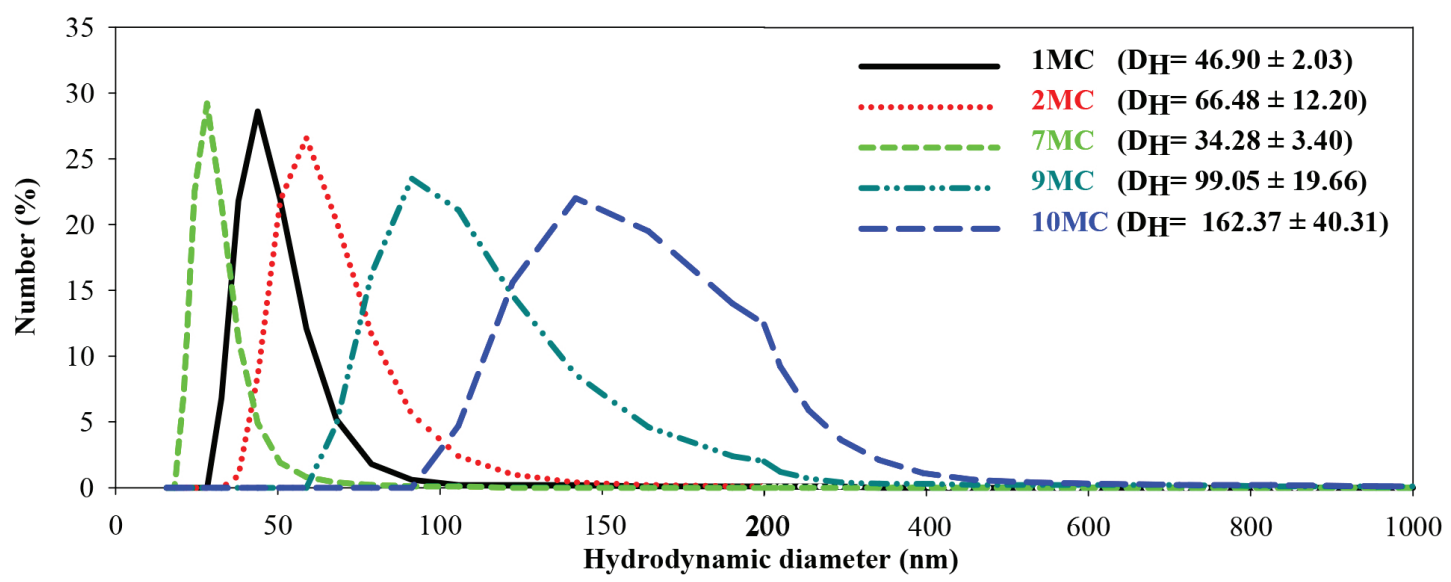

Figure 4. Droplet size distribution of microemulsion of Brazil Nut oil (1, 2, 7, 9 and 10 MC)

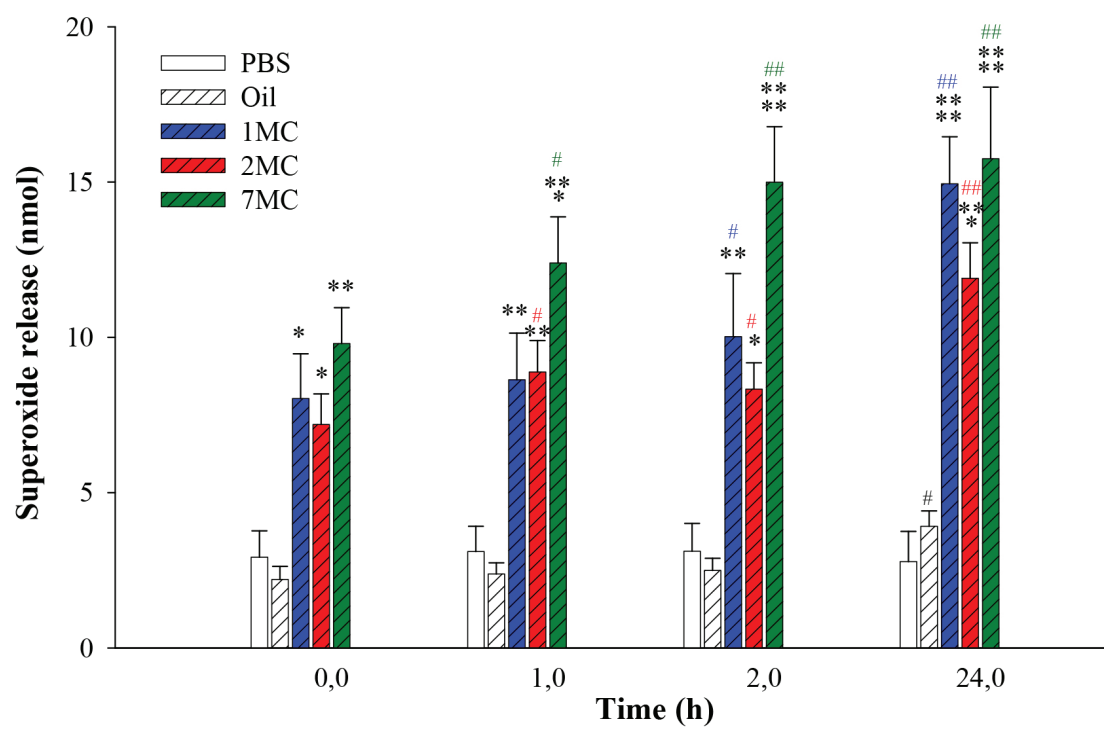

Figure 5. Superoxide release of mononuclear blood phagocytes stimulated by Brazil Nut oil and developed microemulsion formulations (1, 2, and 7MC). (ANOVA) - *Comparing the control group with the group treated considering the incubation time. $F=70.8349$ and $p<0.0001$. \#Compared incubation times to the same treatment. $F=0.1593, p<0.9216 ; F=17.6137, p<0.0001 ; F=18.4008, p<0.0001 ; F=20.0841, p<0.0001 ;$ and $F=12.0997, p<0.0004$. Abbreviations: Phosphate buffer (PBS)

self-emulsifying vehicle. Brazil Nut oil is a natural product that is easily collected from the wild, and can be added to the diet. In this way, it may be an alternative for future immunotherapy applications, in particular for infectious diseases. Therefore, the Brazil Nut oil ME system is an alternative for possible use as an adjuvant or in modified drug delivery systems.

\section{ACKNOWLEDGEMENTS}

The authors are very grateful to Dr. Eduardo Luzia França, Dra. Adenilda Cristina Honório-França and Dra Maria Aparecida Godoy Soler for technical assistance in rheology and dynamic light scattering. Financial support from the Brazilian agency, FAPEMAT/MT is also gratefully acknowledged.

\section{REFERENCES}

1. Mäder, K.; Mehnert, W.; Adv. Drug Deliv. Rev. 2001, 47, 165.

2. Ghosh, V.; Mukherjee, A.; Chandrasekaran, N.; Ultrason. Sonochem. 2013, 20, 338.

3. Pessoa, R. S.; França, E. L.; Ribeiro, E. B.; Abud, N. G.; Honorio, A. C.; Drug Des., Devel. Ther. 2015, 9, 21.
4. Ribeiro, E. B.; Honório-França, A. C.; França, E. L.; Soler, M. A. G.; Protein Pept. Lett. 2016, 23, 626.

5. Krishnamoorthy, B.; Habibur Rahman, S. M.; Tamil Selvan, N.; Hari Prasad, R.; Rajkumar, M.; Siva Selvakumar, M.; Vamshikrishna, K.; Gregory, M.; Vijayaraghavan, C.; J. Nanoparticle Res. 2015, 17.

6. Fryd, M. M.; Mason, T. G.; Annu. Rev. Phys. Chem. 2012, 63, 493.

7. Oliveira, A. G. De; Scarpa, M. V.; Correa, M. A.; Cera, L. F. R.; Formariz, T. P.; Quim. Nova 2004, 27, 131.

8. Wu, C.; Benet, L. Z.; Pharm. Res. 2005, 22, 11.

9. Pestana, K. C.; Formariz, T. P.; Franzini, C. M.; Sarmento, V. H. V; Chiavacci, L. A.; Scarpa, M. V; Egito, E. S. T.; Oliveira, A. G.; Colloids Surf., B. 2008, 66, 253.

10. Djekic, L.; Primorac, M.; Int. J. Pharm. 2008, 352, 231.

11. Lawrence, M. J.; Rees, G. D.; Adv. Drug Deliv. Rev. 2012, 64, 175.

12. Fanun, M.; Curr. Opin. Colloid Interface Sci. 2012, 17, 306.

13. Kreilgaard, M.; Adv. Drug Deliv. Rev. 2002, 54, 77.

14. Mason, T. G.; Wilking, J. N.; Meleson, K.; Chang, C. B.; Graves, S. M.; J. Phys.: Condens. Matter 2006, 18, R635.

15. Flanagan, J.; Kortegaard, K.; Neil Pinder, D.; Rades, T.; Singh, H.; Food Hydrocolloids 2006, 20, 253.

16. Dalmora, M. E.; Oliveira, A. G.; Int. J. Pharm. 1999, 184, 157. 
17. Acharya, D. P.; Hartley, P. G.; Curr. Opin. Colloid Interface Sci. 2012, $17,274$.

18. Constantinides, P. P.; Yiv, S. H.; Int. J. Pharm. 1995, 115, 225.

19. D'Cruz, O. J.; Uckun, F. M.; Contraception 2001, 64, 113.

20. Tamjidi, F.; Shahedi, M.; Varshosaz, J.; Nasirpour, A.; Innov. Food Sci. Emerg. Technol. 2013, 19, 29.

21. Ansari, S. H.; Islam, F.; Sameen, M.; J. Adv. Pharm. Technol. Res. 2012, 3,142 .

22. Atanasov, A. G.; Waltenberger, B.; Pferschy-wenzig, E.; Linder, T.; Wawrosch, C.; Uhrin, P.; Temml, V.; Wang, L.; Schwaiger, S.; Heiss, E. H.; Rollinger, J. M.; Schuster, D.; Breuss, J. M.; Bochkov, V.; Mihovilovic, M. D.; Kopp, B.; Bauer, R.; Dirsch, V. M.; Stuppner, H.; Biotechnol. Adv. 2015, 33, 1582.

23. Apak, R.; Gorinstein, S.; Böhm, V.; Schaich, K. M.; Özyürek, M.; Güçlü, K.; Pure Appl. Chem 2013, 85, 957.

24. Wasule, D. D.; Nawandar, S. Y.; Kaur, H.; World J. Pharm. Sci. 2014, 2 , 1.

25. Nakatsuji, T.; Kao, M. C.; Zhang, L.; Zouboulis, C. C.; Gallo, R. L.; Huang, C.-M.; J. Invest. Dermatol. 2010, 130, 985.

26. Huang, C. M.; Chen, C. H.; Pornpattananangkul, D.; Zhang, L.; Chan, M.; Hsieh, M. F.; Zhang, L.; Biomaterials 2011, 32, 214.

27. França, E. L.; Maynié, J. C.; Correa, V. C.; Correia, U.; Pereira, R.; Batalini, C.; Kusano, C.; Ferrari, B.; Int. J. Phytomed. 2010, 2, 354.

28. França, E. L.; Bitencourt, R. V.; Fujimori, M.; de Morais, T. C.; Calderon, I. de M. P.; Honorio-França, A. C.; J. Microbiol. Immunol. Infect. 2011, 44, 1 .

29. Mazzoni, M. C.; Schmid-Schonbein, G. W.; Cardiovasc. Res. 1996, 32, 709.

30. França, E. L.; Feliciano, N. D.; Silva, K. A.; Kusano, C.; Ferrari, B.; Honorio-frança, A. C.; Bratislava Med. J. 2009, 110, 517.

31. Freitas, S. P.; Freitas-Silva, O.; Miranda, I. C. De; Coelho, M. A. Z.; Ciênc. Tecnol. Aliment. 2007, 27, 14.

32. Ferreira, E. de S.; Silveira, C. da S.; Lucien, V. G.; Amaral, A. S.; Alim Nutr. 2006, 17, 203.

33. Chunhieng, T.; Hafidi, A.; Pioch, D.; Brochier, J.; Montet, D.; J. Braz. Chem. Soc. 2008, 19, 1374.

34. Santos, O. V. dos; Correa, N. C. F.; Lannes, S. C. da S.; Iluminart 2011, 48.

35. Kris-Etherton, P. M.; Hecker, K. D.; Bonanome, A.; Coval, S. M.; Am. J. Med. 2002, 30, 2.

36. Boonme, P.; Krauel, K.; Graf, A.; Rades, T.; Junyaprasert, V. B.; AAPS PharmSciTech 2006, 7, 1.

37. Wilk, K. A.; Zielińska, K.; Hamerska-Dudra, A.; Jezierski, A.; J. Colloid Interface Sci. 2009, 334, 87.

38. Kumar, A.; Kushwaha, V.; Sharma, P. K.; Int. J. Drug Dev. Res. 2014, 6,1 .
39. United States Pharmacopeial, 30 th United States Pharmacopeial Convention: Rockville, MD, 2007.

40. Ribeiro, E. B.; Kelly, P.; Lanes, D.; Galdeano, N.; Chaud, A.; Pessoa, R. S.; Honorio-frança, A. C.; França, E. L.; Sci. Adv. Mater. 2015, 7, 15.

41. Zanin, S. M.; Miguel, M. D.; Chimelli, M. C.; Oliveira, A. B.; Visão Acadêmica 2002, 3, 13.

42. Côrtes, M. A.; França, E. L.; Reinaque, A. P. B.; Scherer, E. F.; Honoriofrança, A. C.; Polímeros 2013, 23, 402.

43. Reinaque, A. P. B.; França, E. L.; Scherer, E. F.; Côrtes, M. A.; Souto, F. J. D.; Honorio-França, A. C.; Drug Des. Devel. Ther. 2012, 6, 209.

44. Lanes, P. K. D.; Ribeiro, E. B.; Chaud, N. G. A.; Pessoa, R. S.; França, E. L.; Honorio-frança, A. C.; Wulfenia J. 2016, 1, 214.

45. Scherer, E. F.; Honorio-França, A. C.; Hara, C. C. P. de; Reinaque, A. P. B.; Côrtes, M. A.; França, E. L.; Sci. Adv. Mater. 2011, 3, 687.

46. Fagundes, D. L. G.; França, E. L.; Hara, C. de C. P.; Honorio-França, A. C.; Int. J. Pharmacol. 2012, 8, 510 .

47. Hara, C. de C. P.; Honório-França, A. C.; Fagundes, D. L. G.; Guimarães, P. C. L.; França, E. L.; J. Nanomater. 2013, 2, 1.

48. Laura, D.; Fagundes, G.; França, E. L.; Morceli, G.; Vieira, M.; Rudge, C.; Mattos, I. De; Calderon, P.; Honorio-frança, A. C.; Clin. Dev. Immunol. 2013, 2013, 1.

49. Cruvinel, W. D. M.; Júnior, D. M.; Antônio, J.; Araújo, P.; Tieko, T.; Catelan, T.; Rev. Bras. Reumatol. 2010, 55, 434.

50. Dale, D. C.; Boxer, L.; Liles, W. C.; Blood J. 2008, 112, 935.

51. Dizdaroglu, M.; Jaruga, P.; Mustafa, B.; Rodriguez, H.; Free Radic. Biol. Med. 2002, 32, 1102.

52. Santana, J. F. B.; Soler, M. a. G.; da Silva, S. W.; Guedes, M. H.; Lacava, Z. G. M.; Azevedo, R. B.; Morais, P. C.; J. Magn. Magn. Mater. 2005, $289,452$.

53. Soler, M. a G.; Báo, S. N.; Alcântara, G. B.; Tibúrcio, V. H. S.; Paludo, G. R.; Santana, J. F. B.; Guedes, M. H.; Lima, E. C. D.; Lacava, Z. G. M.; Morais, P. C.; J. Nanosci. Nanotechnol. 2007, 7, 1069.

54. Onoue, S.; Yamada, S.; Chan, H. K.; Int. J. Nanomedicine 2014, 9, 1025.

55. França, E. L.; Morceli, G.; Fagundes, D. L. G.; Rudge, M. V. C.; Calderon, I. de M. P.; Honório-França, A. C.; APMIS 2011, 2, 710.

56. Franca-Botelho, A. C.; Lopes, R. P.; Franca., J. L.; Gomes, M. A.; Res. J. Parasitol. 2011, 6, 1.

57. Honorio-frança, A. C.; Hara, C. de C. P.; Ormonde, J. V. S.; Nunes, G. T.; França, E. L.; J. Appl. Biomed. 2013, 11, 153.

58. Rassias, A. J.; Marrin, C. A. S.; Arruda, J.; Whalen, P. K.; Beach, M.; Yeager, M. P.; Anesth. Analg. 1999, 88, 1011.

59. Honorio-França, A. C.; Carvalho, M. P. S. M.; Isaac, L.; Trabulsi, L. R.; Scand. J. Immunol. 1997, 46, 59.

60. Morceli, G.; França, E. L.; Magalhães, V. B.; Damasceno, D. C.; Calderon, I. M. P.; Honorio-França, A. C.; Acta Paediatr. 2011, 100, 550 . 